\title{
PiB fails to map amyloid deposits in cerebral cortex of aged dogs with canine cognitive dysfunction
}

\section{Rikke Fast ${ }^{1}$, Anders Rodell ${ }^{2,3}$, Albert Gjedde ${ }^{2,3,4}$, Kim Mouridsen $^{2}$, Aage K. Alstrup $^{3}$, Carsten R. Bjarkam ${ }^{5,6}$, Mark J. West ${ }^{5}$, Mette Berendt ${ }^{1}$ and Arne Møller ${ }^{2,3}$ *}

1 Department of Clinical Veterinary and Animal Sciences, Faculty of Health and Medical Sciences, University of Copenhagen, Frederiksberg, Denmark

${ }^{2}$ Centre of Functionally Integrative Neuroscience (CFIN), Aarhus University, Aarhus, Denmark

${ }^{3}$ Department of Nuclear Medicine and PET Center, Aarhus University Hospital, Aarhus, Denmark

${ }^{4}$ Department of Neuroscience and Pharmacology, Faculty of Health and Medical Sciences, University of Copenhagen, Copenhagen, Denmark

${ }^{5}$ Department of Biomedicine, Faculty of Health, University of Aarhus, Aarhus, Denmark

${ }^{6}$ Department of Neurosurgery, Aarhus University Hospital, Aarhus, Denmark

\section{Edited by:}

P. Hemachandra Reddy, Oregon

Health and Science University, USA

Reviewed by:

Elizabeth Head, University of

Kentucky, USA

Lisa C. Silbert, Oregon Health \&

Science University, USA

*Correspondence:

Arne Møller, PET Center, Centre of

Functionally Integrative

Neuroscience, Aarhus University

Hospital, Norrebrogade 44, Aarhus 8000, Denmark

e-mail: arne@cfin.dk
Dogs with Canine Cognitive Dysfunction (CCD) accumulate amyloid beta $(A \beta)$ in the brain. As the cognitive decline and neuropathology of these old dogs share features with Alzheimer's disease (AD), the relation between $A \beta$ and cognitive decline in animal models of cognitive decline is of interest to the understanding of $A D$. However, the sensitivity of the biomarker Pittsburgh Compound $B(\mathrm{PiB})$ to the presence of $A \beta$ in humans and in other mammalian species is in doubt. To test the sensitivity and assess the distribution of $A \beta$ in dog brain, we mapped the brains of dogs with signs of $\operatorname{CCD}(n=16)$ and a control group $(n=4)$ of healthy dogs with radioactively labeled $\mathrm{PiB}\left(\left[{ }^{11} \mathrm{C}\right] \mathrm{PiB}\right)$. Structural magnetic resonance imaging brain scans were obtained from each dog. Tracer washout analysis yielded parametric maps of $\mathrm{PiB}$ retention in brain. In the CCD group, dogs had significant retention of $\left[{ }^{11} \mathrm{C}\right] \mathrm{PiB}$ in the cerebellum, compared to the cerebral cortex. Retention in the cerebellum is at variance with evidence from brains of humans with $A D$. To confirm the lack of sensitivity, we stained two dog brains with the immunohistochemical marker 6E10, which is sensitive to the presence of both $A \beta$ and $A \beta$ precursor protein (A $\beta P P$ ). The $6 E 10$ stain revealed intracellular material positive for $A \beta$ or $A \beta P P$, or both, in Purkinje cells. The brains of the two groups of dogs did not have significantly different patterns of $\left[{ }^{11} \mathrm{C}\right] \mathrm{PiB}$ binding, suggesting that the material detected with $6 \mathrm{E} 10$ is $\mathrm{A} \beta \mathrm{PP}$ rather than $A \beta$. As the comparison with the histological images revealed no correlation between the $\left[{ }^{11} \mathrm{C}\right] \mathrm{PiB}$ and $\mathrm{A} \beta$ and A $\beta P P$ deposits in post-mortem brain, the marked intracellular staining implies intracellular involvement of amyloid processing in the dog brain. We conclude that PET maps of $\left[{ }^{11} \mathrm{C}\right] \mathrm{PiB}$ retention in brain of dogs with CCD fundamentally differ from the images obtained in most humans with $A D$.

Keywords: canine cognitive dysfunction, Alzheimer's disease, Pittsburgh compound B, beta-amyloid, dog, 6E10 immunohistochemistry

\section{INTRODUCTION}

A prominent explanation of the etiology of Alzheimer's disease (AD) is the amyloid cascade hypothesis (Hardy and Selkoe, 2002; Jack et al., 2010). According to this hypothesis, $A \beta$ has a primary role in the neuropathological changes associated with $\mathrm{AD}$. The deposition of $A \beta$ is considered an early event in the pathogenesis of $A D$, implying that suitable biomarkers of $A \beta$ load would detect early evidence of disease presence (McKhann et al., 2011).

Humans and dogs have coexisted in mutually beneficial partnerships for at least 100,000 years (Vila et al., 1997). Dogs develop signs of behavioral disorder that correlate with neuropathological findings, and aged dogs acquire behavioral deficits of spatial awareness, social interaction, sleeping pattern, house training, and memory and learning. This combination of behavioral symptoms is known as Canine Cognitive Dysfunction (CCD) (Satou et al., 1997; Rofina et al., 2006; Osella et al., 2007; Yu et al., 2011). The decline of cognitive functions correlates with an increase of $A \beta$ deposits in the cerebral cortex of the dog (Colle et al., 2000; Pugliese et al., 2006a; Rofina et al., 2006). The A $\beta$ deposits found in dog brains are primarily of the diffuse type and are of similar amino acid sequence to those observed in humans (Head et al., 1998; Sarasa et al., 2010). Dogs with CCD are therefore of special interest as an animal model of the early events of $\mathrm{AD}$, when $\mathrm{A} \beta$ deposits mainly are of the diffuse type (Pugliese et al., 2006b; Rofina et al., 2006).

A modified form of the amyloid-binding histological dye thioflavin- $\mathrm{T}\left(\left[{ }^{11} \mathrm{C}\right] \mathrm{PiB}\right)$ made non-invasive PET imaging of amyloid deposits possible. Prior to this, visualization of $A \beta$ deposits was only possible using histological post-mortem material (Klunk et al., 2004). Although new potential tracers are becoming available $\left[{ }^{11} \mathrm{C}\right] \mathrm{PiB}$ is the most intensively evaluated marker of $\mathrm{A} \beta$ in human studies with PET (Klunk et al., 2004; Price et al., 2005; Mintun 
et al., 2006; Lockhart et al., 2007; Ikonomovic et al., 2008; Gulyas et al., 2012; Gjedde et al., 2013; Rodell et al., 2013). Compared to cognitively intact control subjects, $\mathrm{AD}$ patients exhibit greater $\left[{ }^{11} \mathrm{C}\right] \mathrm{PiB}$ retention in areas known to contain substantial accumulations of $\mathrm{A} \beta$ deposits, including the frontal and parietal cortices, whereas brain areas relatively unaffected by $A \beta$ pathology, such as the cerebellum, show little or no $\left[{ }^{11} \mathrm{C}\right] \mathrm{PiB}$ retention (Klunk et al., 2004; Price et al., 2005; Ikonomovic et al., 2008).

The specific binding properties of $\left[{ }^{11} \mathrm{C}\right] \mathrm{PiB}$ are still controversial, as is the correlation with the post-mortem histology of tissue taken from disease models established in animals (Klunk et al., 2005a; Toyama et al., 2005; Bacskai et al., 2007; Rosen et al., 2011). The tracer is known to pass the blood-brain barrier with comparative ease, which renders the uptake sensitive to blood flow differences, as well as amyloid load (Blomquist et al., 2008; Gjedde et al., 2013). Also, as a dye, Pittsburgh compound B (PiB) has varying affinities for different tissue components and for different multimeric assemblies of $A \beta$ and $A \beta$ precursor protein $(A \beta P P)$. Thus, $\mathrm{PiB}$ binding to specific subtypes of amyloid is at variance with, and often much lower in mice and non-human primates, than in humans, despite substantial $\mathrm{A} \beta$ deposits in these species (Klunk et al., 2005b; Rosen et al., 2008; Manook et al., 2012). According to Rosen et al. (2010), it is possible that $\mathrm{PiB}$ recognizes a specific site in multimeric $A \beta$ that is peculiar to most humans with $\mathrm{AD}$, but may be unavailable in some humans and in other mammalian species.

It is not yet known whether tracer $\left[{ }^{11} \mathrm{C}\right] \mathrm{PiB}$ detects $\mathrm{A} \beta$ deposits in dogs. To test if the tracer actually detects $A \beta$ deposits in a cohort of dogs with a clinical diagnosis of CCD, in comparison with unaffected control dogs, and thus effectively reveals the known distribution of $A \beta$ in this species, we obtained $\left[{ }^{11} \mathrm{C}\right] \mathrm{PiB}$ PET images from the brains of animals in these two groups.

\section{MATERIALS AND METHODS}

According to the experimental design, PET images were obtained from dog brains using an HRRT CPS Innovations tomograph, and MR images were subsequently co-registered for each dog brain. The binding capacity for each brain region was assessed by analysis of regional washout rates. Immunohistochemical analysis was performed on brain sections from two dogs using a monoclonal mouse antibody against the amino acid residue $1-16$ of $\mathrm{A} \beta$ (6E10).

The study population consisted of a group of dogs with a clinical diagnosis of CCD $(n=16)$ and a control group of cognitively normal dogs $(n=4)$. Dogs were recruited from the Small Animal University Hospital at The Department of Clinical Veterinary and Animal Sciences, University of Copenhagen or through referring veterinarians.

The study was approved by the ethics committee at The Department of Clinical Veterinary and Animal Sciences, Faculty of Health and Medical Sciences, University of Copenhagen, Denmark.

\section{CCD GROUP}

The study population consisted of 16 geriatric dogs with a diagnosis of CCD, including nine males and seven females, with an average age of 12.6 years (range 9-17 years; SD 2.2 years). All dogs had a clinical and neurological examination, standard hematological and chemical profiles including thyroid panel showing no evidence of systemic or neurological disease, which could mimic clinical signs of CCD. All dogs had magnetic resonance imaging (MRI) that showed no signs of intracranial lesions that might give rise to clinical signs mimicking CCD. A clinical diagnosis of CCD was established after evaluation with a validated owner questionnaire that targeted signs of CCD and was further supported by the finding of significant brain atrophy on MRI images by means of stereology [Cavalieri principle; (Kiatipattanasakul et al., 1996; Rofina et al., 2006)].

\section{CONTROL GROUP}

The group of control dogs consisted of four dogs aged 5-12 years (mean 8.8 years, SD 3.3), three males and one female. The dogs had a normal clinical and neurological examination and standard hematological and chemical profiles including thyroid panel and showed no signs of systemic disease. All dogs had a normal MRI. The dogs were defined as having normal cognitive behavior based on absence of signs of CCD, as assessed by owner interviews, using the same validated questionnaire used for the CCD group.

Details of the study group are listed in Table 1.

\section{IMAGING PROCEDURES}

PET images of the dog brains were obtained with the HRRT CPS Innovations tomograph mainly used for animal model research. Before PET, each dog was sedated with an intramuscular injection of diazepam $0.4-0.7 \mathrm{mg} / \mathrm{kg}$ and methadone $0.2-0.4 \mathrm{mg} / \mathrm{kg}$. Two catheters were placed either in the cephalic or saphenous veins, depending on accessibility, one for the combined administration of anesthesia and maintenance fluids and one for the administration of $\left[{ }^{11} \mathrm{C}\right] \mathrm{PiB}$. Anesthesia was induced by intravenous injection

Table 1 | Information regarding age, sex, weight, and breed for the study population.

\begin{tabular}{|c|c|c|c|c|}
\hline & Age & Sex & Weight (kg) & Breed \\
\hline \multirow[t]{16}{*}{ CCD group } & 13 & M & 15.6 & Beagle \\
\hline & 13 & M & 2.7 & Chihuahua \\
\hline & 12 & $\mathrm{~F}$ & 10.0 & Cocker Spaniel \\
\hline & 13 & $\mathrm{~F}$ & 19.0 & Tervueren \\
\hline & 10 & $\mathrm{~F}$ & 33.0 & German Shepherd \\
\hline & 11 & $M$ & 12.2 & Cairn Terrier \\
\hline & 15 & M & 8.1 & Dachshund \\
\hline & 11 & M & 15.6 & Catalonian sheepdog \\
\hline & 17 & M & 12.5 & Small mix \\
\hline & 14 & $\mathrm{~F}$ & 7.9 & Jack Russell \\
\hline & 9 & M & 28.0 & Labrador \\
\hline & 11 & M & 38.0 & German Wirehaired Pointer \\
\hline & 13 & $\mathrm{~F}$ & 28.0 & Labrador \\
\hline & 13 & $\mathrm{~F}$ & 22.0 & Border Collie \\
\hline & 11 & $M$ & 20.0 & Beagle \\
\hline & 16 & $M$ & 10.0 & Kooikerhondje \\
\hline \multirow[t]{4}{*}{ Control group } & 7 & $M$ & 30.0 & Tervueren \\
\hline & 11 & $M$ & 31.0 & Groenendal \\
\hline & 5 & $M$ & 26.5 & Tervueren \\
\hline & 12 & $\mathrm{~F}$ & 21.0 & Tervueren \\
\hline
\end{tabular}


of propofol $4 \mathrm{mg} / \mathrm{kg}$. Following intubation, anesthesia was maintained by a continuous rate infusion of propofol $4-6 \mathrm{mg} / \mathrm{kg} / \mathrm{h}$ (Grasby 3400 Anesthesia Pump, Groendorf Medicine, Hørsholm, Denmark) and the dog was placed in dorsal recumbency with the head positioned in the scanner field. Each dog was carefully positioned in a deflatable Kroeyer bag in order to minimize individual positioning variability between scans. Respiration was maintained with a ventilator (Hallowell EMC Model 200 Veterinary Anesthesia Ventilator, Hallowell EMC, Pittsfield, MA, USA), and heart rate was monitored by ECG, Oxygen saturation through a pulse oximeter and blood pressure through a pediatric blood pressure cuff placed on one of the hind extremities. One monitor (MP9000 Mindray Patient Monitor, Shenzhen Mindray Bio-medical Electronics Co., Hamburg, Germany) registered all parameters. The dogs received Lactated Ringer's solution from an infusion pump (Baxter) throughout the anesthesia at a maintenance rate of $10 \mathrm{ml} / \mathrm{kg} / \mathrm{h}$. All dogs were fasted for at least $12 \mathrm{~h}$ prior to imaging to reduce anesthetic risk.

Each dog was injected intravenously with $84-333 \mathrm{MBq}[N-$ methyl- $\left.{ }^{11} \mathrm{C}\right] 2$-( $4^{\prime}$-methylaminophenyl)-6-hydroxybenzothiazole $\left(\left[{ }^{11} \mathrm{C}\right] \mathrm{PiB}\right)$ dissolved in $10 \mathrm{ml}$ of sterile isotonic saline. PET emission data were collected for 90 min preceded by a transmission scan, commencing with the injection of $\left[{ }^{11} \mathrm{C}\right] \mathrm{PiB}$.

We used 30 min MRI with 3 T GE Signa HDxt - Twin speed gradient system to obtain anatomical regions of interest (RIO) (General Electric Medical Systems, Milwaukee, WI, USA). The dogs were placed headfirst into the magnet bore, and an 8-channel GE head coil was secured over the head of the animal. The scanner allowed for acquisition of high-resolution anatomy imaging in contiguous $1 \mathrm{~mm}$ thick transverse slices using three dimensional spoiled gradient echo (SPGR), pulse sequence $(\mathrm{TE}=2.9 \mathrm{~ms}$, $\mathrm{TR}=6.7 \mathrm{~ms}$, flip angle $=14^{\circ}$ ).

\section{GENERATION OF AN MR TEMPLATE BRAIN}

No template is available for the co-registration of dogs to a standard 3-D imaging volume, so we constructed a reference template from the MRI anatomical image of one control dog brain. For orientation purposes, the T1-weighted MRI volume of the brain of this dog was linearly registered to an in-house template space of Danish Landrace pigs. The registration was performed using the MINC registration software package from Montreal Neurological Institute (MNI) (Collins et al., 1994). This pig atlas was constructed as described in previous investigations (Maes et al., 1997; Watanabe et al., 2001; Andersen et al., 2005). This control dog brain image was used as a reference space for the subsequent intersubject co-registration of all dog brains in the study. For each dog, the T1-weighted MRI brain volume was manually cropped to initially remove extracerebral tissue, and the image was corrected for non-uniformity in the image intensity (Sled et al., 1998). The MR-image was then registered to the dog model space using a 12 parameter affined transformation (Maes et al., 1997). The images were resampled to isotropic resolution of $0.5 \mathrm{~mm} \mathrm{3-D}$ resolution, the cerebral tissue was skull-stripped using the registration, and a brain mask defined on the dog template. We used this skull-stripped MRI as a target for the subsequent MRI-PET registrations of dog brains.

\section{RECONSTRUCTION OF [ $\left.{ }^{11} \mathrm{C}\right]$ PIB IMAGES}

For each PET image, the dynamic files were averaged over the time dimension and the average image was blurred using a Gaussian kernel to a full width at half maximum (FWHM) of $4.0 \mathrm{~mm}$. The blurred image was then linearly registered using a rigid body affined transformation and mutual information criteria (Collins et al., 1994; Maes et al., 1997). Each dynamic and averaged PET image was spatially normalized using the corresponding concatenated transform from PET to MRI to model space. This spatial normalization was performed using the MNI software package. As no consensus exists on the specific anatomic localization of the different canine brain cortical regions, we used a segregation of cortical regions that largely agrees with the canine stereotaxic brain anatomy atlas (Dua-Sharma et al., 1970).

\section{IDENTIFICATION OF BRAIN REGIONS}

In order to extract image values for relevant regional brain areas, we manually segmented the model dog brain image into specific RIO, which included cortical regions and the cerebellum; frontal, temporal, parietal, and occipital cortices and the cerebellum (Figure 1), with initial tissue segmentation of gray matter, white matter, and CSF classes with an automated method (Cocosco et al., 2003). We then manually parcellated each image into the relevant regions for each tissue class and obtained regional parametric estimates of $\mathrm{PiB}$ binding from each of these template regions.

\section{PARAMETRIC MAPPING OF PIB RETENTION}

The brain uptake of $\left[{ }^{11} \mathrm{C}\right] \mathrm{PiB}$ largely is flow-limited, with an extraction fraction of more than 50\% (Blomquist et al., 2008). Therefore, we determined the binding capacity by analysis of regional washout rates, which decline in the presence of binding (Moller et al., 2009). We used washout analysis because unmetabolized $\left[{ }^{11} \mathrm{C}\right] \mathrm{PiB}$ disappears rapidly from the circulation and the consequent brief exchange with brain tissue implies that retention of intact tracer in brain tissue depends on the washout rate and not on a continued exchange between compartments of tracer in the tissue and circulation after the period of initial entry of tracer into the tissue, which ends approximately at $4 \mathrm{~min}$ after injection (Rodell et al., 2013). Also, we chose this method because we initially had no evidence of the presence of a specific reference region devoid of displaceable binding of $\left[{ }^{11} \mathrm{C}\right] \mathrm{PiB}$ in dog brain.

To parametrically map neuroreceptors in relevant cases, a reference region eliminates the need to determine the arterial concentrations of the tracer, particularly when tracer retention is subject washout limitation only (Edison et al., 2012). In brain, amyloid deposits are present in the cerebellum in genetic $\mathrm{AD}$, as cerebral amyloid angiopathy, but also in prion diseases (Villemagne et al., 2012). The choice of an alternative method of identification of a reference region for the analysis of $\left[{ }^{11} \mathrm{C}\right] \mathrm{PiB}$ binding therefore was necessary in the present case (Moller et al., 2009; Edison et al., 2012). The chosen method specifically applies to tracers with the kinetic behavior of $\mathrm{PiB}$. It identifies a suitable reference region in the brain when one exists, by locating the area of least $\left[{ }^{11} \mathrm{C}\right] \mathrm{PiB}$ binding, considered most suitable for this purpose.

Using the in-house developed software, we extracted mean $\left[{ }^{11} \mathrm{C}\right] \mathrm{PiB}$ binding values within specific ROIs from the parametric images and submitted region-based analysis. Figure $\mathbf{1}$ shows the 


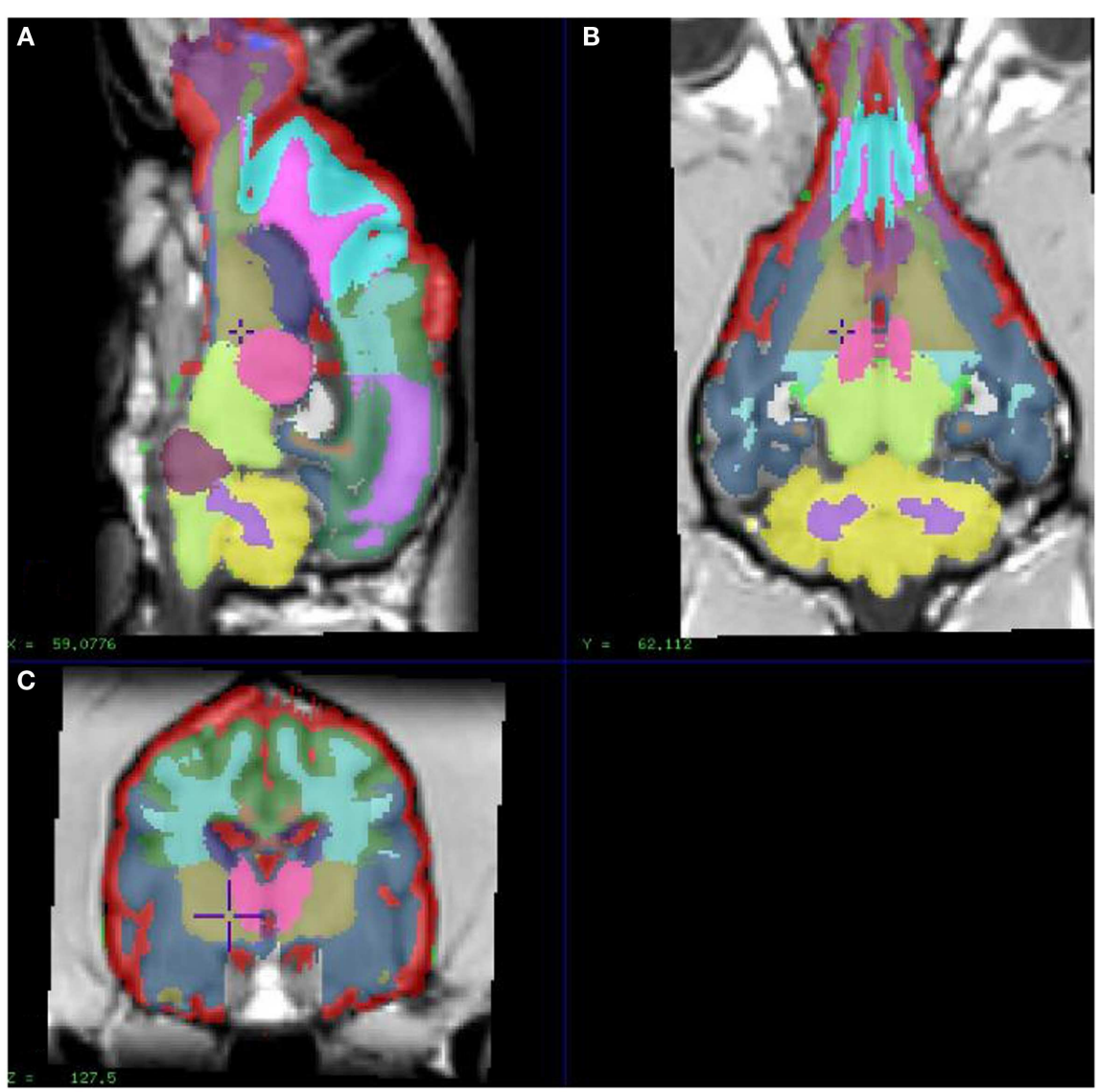

FIGURE 1 | Showing different sections of a dog brain with the ROI as color coded areas outlined by the authors based on a stereotaxic atlas by Dua-Sharma, in order to extract PET image values for relevant regional brain areas (Dua-Sharma et al., 1970). (A) Sagittal mid section of a dog brain with identification of ROI. (B) Dorsal section of dog brain at the level of the third ventricle and caudate nucleus with identification of ROI. (C) Transverse section of dog brain at the level of the third and lateral ventricles and the habenular nucleus with identification of ROI. Color code identifies the gray matter for each ROI used. ROI, regions of interest.
ROIs used to extract the binding values. The binding potential $\mathrm{BP}_{\mathrm{ND}}$ of $\left[{ }^{11} \mathrm{C}\right] \mathrm{PiB}$ was estimated from the washout measure, in relation to the identified region of reference (Moller et al., 2009). We chose the reference region by first locating the voxels of maximum washout rates, identified by means of the washout index $\Theta$ that equals the ratio of the twice to once integrated timeradioactivity records of tracer in the voxels. The faster the washout, and hence the lower the specific binding, the higher the magnitude of the washout index $\Theta$ (Moller et al., 2009).

\section{HISTOLOGY AND IMMUNOHISTOCHEMISTRY}

Two CCD dog brains underwent ex vivo histopathological investigation. After sacrifice, we quickly removed and immersed the brains in $10 \%$ neutral buffered formalin until further processing. From each brain, we embedded one hemisphere in alginate and sectioned it coronally into $9 \mathrm{~mm}$ thick slabs as directed by the previously obtained MRI/PET images (Sorensen et al., 2000; Bjarkam et al., 2001). We immersed the brain slabs in $30 \%$ sucrose for 5 days, froze them with gaseous CO mounted in a cryostat, and then sectioned them further into 20 series of $40 \mu \mathrm{m}$ thick coronal sections. The resulting sections were mounted on microslides and subsequently stained with Nissl-, AMG, HE, or Congo Red/Thioflavin S, according to standard protocols, or stored freely floating in De Olmos solution for subsequent immunohistochemical staining procedures (Nielsen et al., 2007). We performed immunohistochemical analysis on the freely floating sections with a monoclonal mouse antibody against the amino acid residue $1-16$ of $\mathrm{A} \beta$ (6E10) (Cat \# SIG39320) (Covance, CA, USA), which does not distinguish between $\mathrm{A} \beta \mathrm{PP}$ and $\mathrm{A} \beta$ (Aho et al., 2010). We pretreated sections for $10 \mathrm{~min}$ with $70 \%$ formic acid to expose antigenic sites and then incubated the sections in primary antibody diluted 1:2000 in Tris buffered saline with $1 \%$ Triton $+0.2 \%$ milk overnight at $4^{\circ} \mathrm{C}$, before visualization with a secondary goat anti-mouse IgG diluted 1:400 in Tris buffered saline with $1 \%$ Triton $+0.2 \%$ milk for $1 \mathrm{~h}$ at room temperature. We visually assessed the staining by light microscopy of $6 \mathrm{E} 10$-immunostained sections from the cerebral cortex and the cerebellum.

\section{STATISTICAL ANALYSIS}

We analyzed differences among ROI estimates of $\left[{ }^{11} \mathrm{C}\right] \mathrm{PiB}$ binding in both gray and white matter with paired-to-sample $t$-test. 
Group differences were tested with permutation tests, due to the small sample size in the control group, in whole brain, as well as in specific cortical regions. Due to the age span of the cohort, we also assessed group differences after correction for age with regression analysis. A probability of $p<0.05$ was considered a statistically significant non-random result.

\section{RESULTS}

In the CCD group $\left[{ }^{11} \mathrm{C}\right] \mathrm{PiB}$ binding was significantly higher in the gray matter of the cerebellum, than in the frontal $(p<0.001)$, temporal $(p<0.001)$, parietal $(p<0.001)$, and occipital $(p<0.001)$ lobes. Thus, the voxel maps of the washout index $(\Theta(T))$ values did not confirm the prediction of the cerebellum as a suitable reference region. We chose the reference area to be all voxels in which the value of $\Theta$ equaled or exceeded $95 \%$ of the maximum value of $\Theta(2170$ s). Surprisingly, we found this reference region to be situated in the temporal cortex (Figure 2). Greater PiB binding was seen in the gray matter of the occipital lobe, compared with the frontal and temporal lobes, with $p=0.03$ and $p=0.003$, respectively, for these comparisons. In addition, the $\left[{ }^{11} \mathrm{C}\right] \mathrm{PiB}$ reached significantly higher binding in the gray matter in the parietal lobe than in the temporal lobe $(p<0.001)$ (Table 2). The maps revealed differential regional $\left[{ }^{11} \mathrm{C}\right] \mathrm{PiB}$ binding, with the highest binding in the cerebellum.

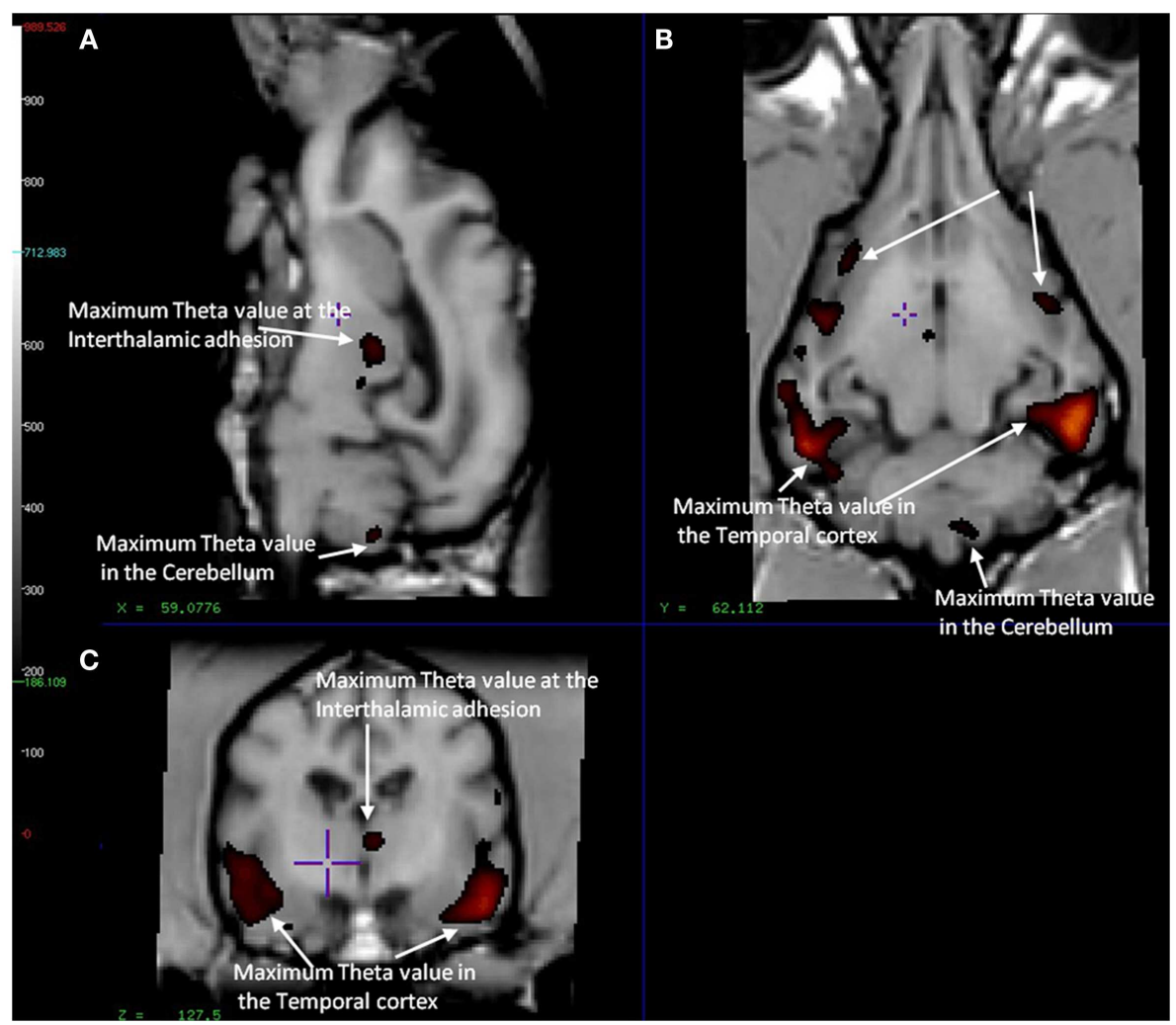

FIGURE 2 | Magnetic resonance imaging of the brain of CCD dogs with reference region of max average theta value (red/dark red) identical with an area of maximal washout characteristics of [11C]PiB highlighted in red and therefore minimum binding of [11C]PiB. (A) Mid-sagittal section of dog brain showing an area of max theta value (red/dark red) and therefore minimum [11 C]PiB binding in the thalamic adhesion and the cerebellum.
(B) Dorsal section of dog brain at the level of the third ventricle and caudate nucleus. Showing areas of max theta value (red/dark red) in the parietal and temporal lobes. (C) Transverse section of dog brain at the level of the third and lateral ventricles and the habenular nuclei. Identifying areas of maximum theta (red/dark red) and therefore minimum [11 C]PiB binding in the temporal lobes and the thalamic adhesion.

Table 2 | Mean $\mathrm{BP}_{\mathrm{ND}}$ for $\left[{ }^{11} \mathrm{C}\right] \mathrm{PiB}$ in different ROI determined by the Hypotime method for gray and white matter in the CCD group.

\begin{tabular}{|c|c|c|c|c|c|}
\hline & Cerebellum & Frontal cortex & Temporal cortex & Parietal cortex & Occipital cortex \\
\hline Gray matter (mean BP $P_{\mathrm{ND}}$ ) & 0.35 & 0.23 & 0.22 & 0.24 & 0.26 \\
\hline Cerebellum vs. other ROI $(p<)$ & & 0.001 & 0.001 & 0.001 & 0.001 \\
\hline White matter (mean BP ${ }_{\mathrm{ND}}$ ) & 0.39 & 0.23 & 0.25 & 0.24 & 0.25 \\
\hline Cerebellum vs. other ROI $(p<)$ & & 0.001 & 0.001 & 0.001 & 0.001 \\
\hline
\end{tabular}

$B P_{N D}$, binding potential; PiB, Pittsburg compound B; $C C D$, canine cognitive dysfunction; ROI, regions of interest.

$p$-Values for difference in mean $B P_{N D}$ between different $R O I$. 
Table 3 | showing mean $\mathrm{BP}_{\mathrm{ND}}$ for $\left[{ }^{11} \mathrm{C}\right] \mathrm{PiB}$ determined by the Hypotime method.

\begin{tabular}{|c|c|c|c|c|c|c|c|c|c|c|}
\hline Dog id & $\begin{array}{l}\text { Gray } \\
\text { matter } \\
\text { Mean } \mathrm{BP}_{\mathrm{ND}}\end{array}$ & $\begin{array}{l}\text { White } \\
\text { matter } \\
\text { Mean BP }\end{array}$ & $\begin{array}{l}\text { Frontal } \\
\text { lobe } \\
\text { Gray } \\
\text { matter } \\
\text { Mean } \mathrm{BP}_{\mathrm{ND}}\end{array}$ & $\begin{array}{l}\text { Frontal } \\
\text { lobe } \\
\text { White } \\
\text { matter } \\
\text { Mean BP }\end{array}$ & $\begin{array}{l}\text { Temporal } \\
\text { lobe } \\
\text { Gray } \\
\text { matter } \\
\text { Mean } \mathrm{BP}_{\mathrm{ND}}\end{array}$ & $\begin{array}{l}\text { Temporal } \\
\text { lobe } \\
\text { White } \\
\text { matter } \\
\text { Mean BP }\end{array}$ & $\begin{array}{l}\text { Parietal } \\
\text { lobe } \\
\text { Gray } \\
\text { matter } \\
\text { Mean BP }\end{array}$ & $\begin{array}{l}\text { Parietal } \\
\text { lobe } \\
\text { White } \\
\text { matter } \\
\text { Mean BP }\end{array}$ & $\begin{array}{l}\text { Occipital } \\
\text { lobe } \\
\text { Gray } \\
\text { matter } \\
\text { Mean BP }\end{array}$ & $\begin{array}{l}\text { Occipital } \\
\text { lobe } \\
\text { White } \\
\text { matter } \\
\text { Mean BP }\end{array}$ \\
\hline \multicolumn{11}{|c|}{ CCD GROUP } \\
\hline 1108 & 0.36918 & 0.41686 & 0.25736 & 0.27780 & 0.23450 & 0.27309 & 0.28551 & 0.29090 & 0.32647 & 0.32177 \\
\hline 3252 & 0.29433 & 0.33419 & 0.22862 & 0.22355 & 0.21422 & 0.25950 & 0.24485 & 0.22384 & 0.21768 & 0.22302 \\
\hline 18361 & 0.43665 & 0.34678 & 0.39350 & 0.37690 & 0.41874 & 0.38073 & 0.39839 & 0.34483 & 0.32867 & 0.20188 \\
\hline 24503 & 0.36242 & 0.37585 & 0.30868 & 0.33663 & 0.39035 & 0.39897 & 0.36618 & 0.38278 & 0.33793 & 0.39035 \\
\hline 27168 & 0.38462 & 0.51318 & 0.19780 & 0.20738 & 0.16561 & 0.21138 & 0.19474 & 0.20348 & 0.20727 & 0.22843 \\
\hline 27055 & 0.28487 & 0.29230 & 0.24726 & 0.24043 & 0.18862 & 0.19913 & 0.22122 & 0.19580 & 0.24063 & 0.22283 \\
\hline 27777 & 0.37050 & 0.50813 & 0.16553 & 0.15198 & 0.16889 & 0.17265 & 0.16966 & 0.16724 & 0.21399 & 0.21677 \\
\hline 26494 & 0.30800 & 0.28431 & 0.19754 & 0.16082 & 0.15024 & 0.16348 & 0.17263 & 0.16019 & 0.17932 & 0.16612 \\
\hline 26281 & 0.16585 & 0.17314 & 0.15036 & 0.11858 & 0.15762 & 0.16479 & 0.20272 & 0.19863 & 0.20245 & 0.24843 \\
\hline 27123 & 0.52081 & 0.55678 & 0.37785 & 0.38499 & 0.46538 & 0.55397 & 0.53145 & 0.54140 & 0.46887 & 0.48173 \\
\hline 29415 & 0.32971 & 0.42708 & 0.19442 & 0.20514 & 0.14215 & 0.15619 & 0.17425 & 0.17719 & 0.17228 & 0.15003 \\
\hline 24324 & 0.49174 & 0.71424 & 0.29807 & 0.30279 & 0.31701 & 0.40795 & 0.33796 & 0.34689 & 0.41262 & 0.34943 \\
\hline 23620 & 0.28615 & 0.25388 & 0.16042 & 0.15720 & 0.13067 & 0.14567 & 0.14248 & 0.12801 & 0.22083 & 0.19170 \\
\hline 26410 & 0.32704 & 0.41380 & 0.13108 & 0.12207 & 0.11948 & 0.15642 & 0.11477 & 0.09918 & 0.19422 & 0.15573 \\
\hline 20041 & 0.28830 & 0.26793 & 0.18012 & 0.15675 & 0.13928 & 0.15471 & 0.15767 & 0.14654 & 0.16238 & 0.15333 \\
\hline 29165 & 0.36743 & 0.40270 & 0.20472 & 0.21982 & 0.18953 & 0.23377 & 0.20293 & 0.21934 & 0.26152 & 0.24769 \\
\hline \multicolumn{11}{|c|}{ CONTROL GROUP } \\
\hline 31036 & 0.25143 & 0.31536 & 0.17511 & 0.18550 & 0.12698 & 0.15761 & 0.17070 & 0.18368 & 0.18761 & 0.19417 \\
\hline 31097 & 0.32839 & 0.48010 & 0.27697 & 0.26922 & 0.21317 & 0.29735 & 0.26637 & 0.28353 & 0.29711 & 0.28859 \\
\hline 31140 & 0.36561 & 0.37084 & 0.26716 & 0.30053 & 0.19079 & 0.23095 & 0.27198 & 0.26645 & 0.26197 & 0.26120 \\
\hline 27351 & 0.26679 & 0.28976 & 0.19716 & 0.18982 & 0.14679 & 0.17281 & 0.17080 & 0.15745 & 0.20649 & 0.18540 \\
\hline
\end{tabular}

$B P_{N D}$. Mean binding potential of ${ }^{11}$ CJPiB calculated using the Hypotime method.

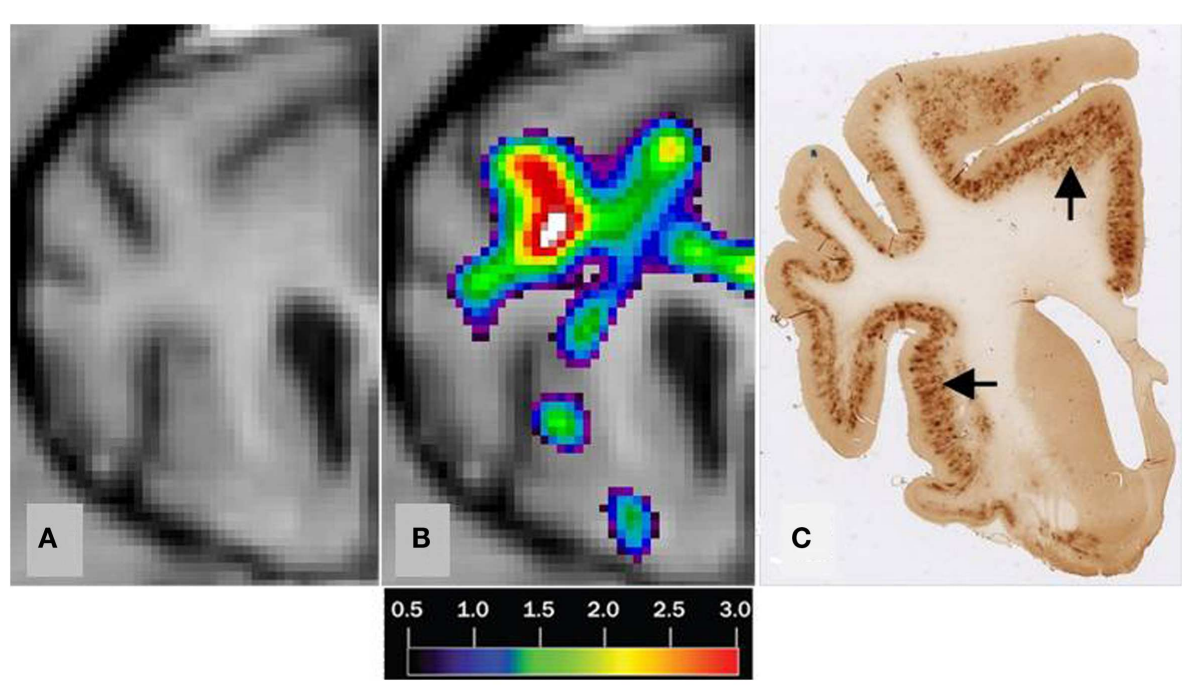

FIGURE 3 | Correlation of MRI [ $\left.{ }^{11} \mathrm{C}\right] \mathrm{PiB}$ PET imaging and histopathology of a transverse brain section at the level of the rostral commissure and the corpus striatum. The brain is from a 17-year old small mixed breed male dog with clinical diagnosis of CCD. (A) Transverse $\mathrm{MRI}$ of brain from CCD dog at the level of rostral commissure and the corpus striatum (B) MRI from picture 1 and corresponding $\left[{ }^{11} \mathrm{C}\right] \mathrm{PiB}$ PET imaging. $\left[{ }^{11} \mathrm{C}\right] \mathrm{PiB}$ binding is indicated by a color scale with red indicating high retention and black indicating low retention. Calculated using the Hypotime method. (C) Corresponding section to 1 and 2 immunostained with amyloid $(A \beta)$ monoclonal antibody 6E10. Dark areas identifies positive areas of immunostaining using $6 \mathrm{E} 10$ indicating and thereby either $A \beta$ and A $\beta P P$ deposits or both (Marked with arrows). MRI, magnetic resonance imaging; PiB, Pittsburgh compound B; PET, positron emission tomography; $C C D$, canine cognitive dysfunction. 
For white matter, significantly higher $\left[{ }^{11} \mathrm{C}\right] \mathrm{PiB}$ binding occurred in the cerebellum compared to the frontal, temporal, parietal, and occipital lobes $(p<0.001)$ (Table 2), with mean estimates of $\left[{ }^{11} \mathrm{C}\right] \mathrm{PiB}$ binding potentials $\left(\mathrm{BP}_{\mathrm{ND}}\right)$ listed in Table 3 for all ROIs.

We found no significant differences of $\left[{ }^{11} \mathrm{C}\right] \mathrm{PiB}$ binding between the CCD and control groups in any ROI. Neither did we find any correlation between the in vivo $\left[{ }^{11} \mathrm{C}\right] \mathrm{PiB}$ accumulation in images obtained with PET, and the ex vivo matched measures of $\mathrm{A} \beta$ and $\mathrm{A} \beta \mathrm{PP}$ staining post-mortem (Figure 3 ), consistent with the observation that neocortex had very little signal from $\left[{ }^{11} \mathrm{C}\right] \mathrm{PiB}$, in contrast to the extensive immunohistochemical staining of diffuse extracellular $A \beta$ and $A \beta P P$ deposits (Figure 4). The one region of the brain that did have significant labeling with $\left[{ }^{11} \mathrm{C}\right] \mathrm{PiB}$, the cerebellum, also had marked intracellular staining of $A \beta$ or $A \beta P P$, or both, in the Purkinje cells, and diffuse $A \beta$ and $A \beta P P$ staining of the granule cell and molecular layers (Figure 5). The two dogs with immunohistochemical staining did not show any Nissl, AMG, HE, or Congo Red/Thioflavin positive amyloid deposits.

\section{DISCUSSION}

We present the first evidence that PET images of the distribution of $\left[{ }^{11} \mathrm{C}\right] \mathrm{PiB}$ retention in brain of dogs with CCD fundamentally are different from the images obtained in most humans with AD. Unlike the general evidence of uptake in brain of humans with $\mathrm{AD}$, the evidence in this study revealed the highest uptake in the cerebellum of the dogs with CCD and not in the neocortical regions. We noted the least retention of the biomarker in the temporal cortex (Figure 2). To obtain this finding, we mapped unto the brain images an index of the biomarker washout, the washout index $\Theta$,

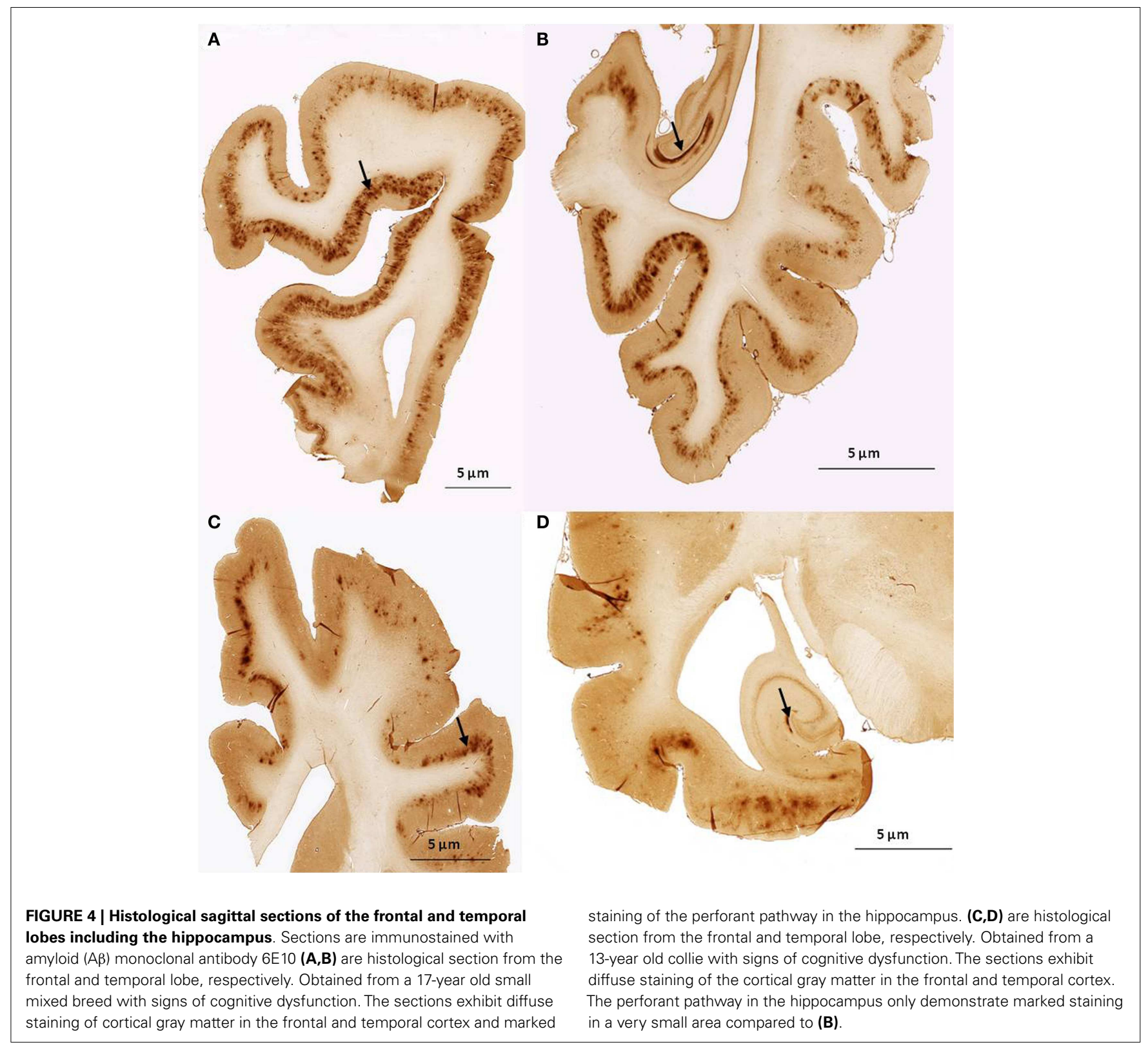



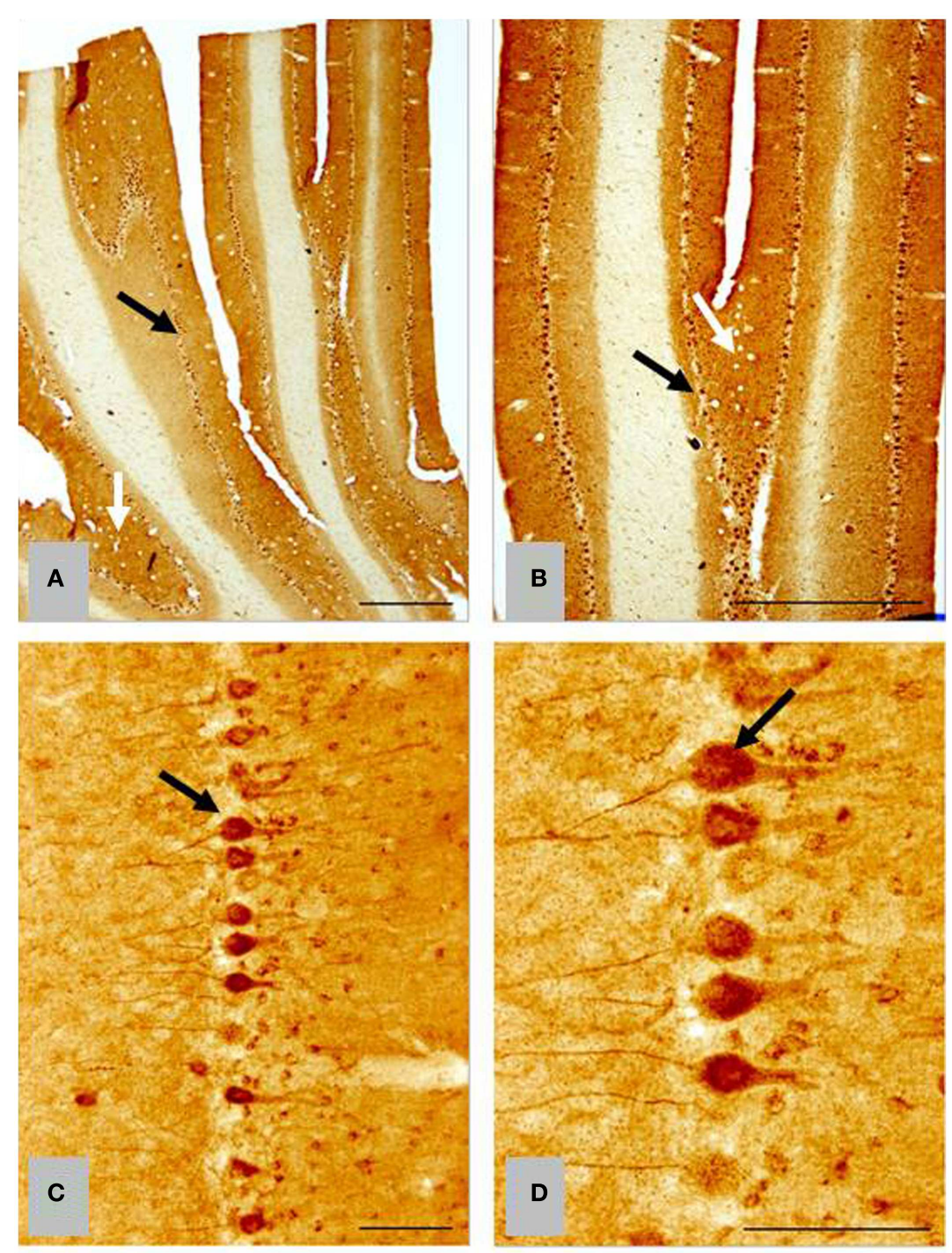

scalebars: $a, b=1000 \mu \mathrm{m} ; \mathrm{c}, \mathrm{d}=100 \mu \mathrm{m}$

FIGURE 5 | Histological horizontal sagittal sections through the anterior lobe of the cerebellum. Obtained from a 13-year old female Border Collie with clinical signs of canine cognitive dysfunction. (A,B) Low magnification view immunostained with amyloid $(A \beta)$ monoclonal antibody 6 E10 showing the presence of marked immunostaining of Purkinje cells (black arrows), but also exhibiting diffuse staining of the granular and molecular layer (white arrows). (C,D) High magnification view of Purkinje cells in

$(\mathbf{A}, \mathbf{B})$ showing intracellular accumulation of $A \beta$ positive material. $C C D$, canine cognitive dysfunction. which rises with the rate of washout. From the retention of the biomarker, we concluded that the cerebellum gray matter in the dog brain would not be an appropriate reference region for binding of $\left[{ }^{11} \mathrm{C}\right] \mathrm{PiB}$ in dogs, a finding that is at variance with studies of human $\mathrm{AD}$, in whom the cerebellum shows little $\left[{ }^{11} \mathrm{C}\right] \mathrm{PiB}$ binding and is an appropriate reference region (Klunk et al., 2004; Ikonomovic et al., 2008; Rodell et al., 2013).

Comparison with the images of the histological material revealed no correlation between the images of $\left[{ }^{11} \mathrm{C}\right] \mathrm{PiB}$ and the $\mathrm{A} \beta$ and $\mathrm{A} \beta \mathrm{PP}$ deposits in post-mortem brain, despite marked intracellular staining of $A \beta / A \beta P P$ in the Purkinje cells and diffuse staining of the granule and molecular cell layers. The marked intracellular staining implies intracellular involvement of amyloid processing in the dog brain (Figure 5).

We used the washout-dependent time variable $\Theta$ to identify an alternative region of reference and to calculate binding potentials. The key to the analysis is the time variable $\Theta$, which is related to and serves as an index of the rate of washout and hence of the degree of expansion of the apparent volume of distribution of the tracer occasioned by binding. By this approach, we found areas of rapid clearance in small areas of the temporal cortex (Figure 2), which we chose as regions of reference. As defined by us, the borders 
of the reference region enclosed an area in which the values of $\Theta$ equaled or exceeded $95 \%$ of the maximum mean value of the time variable $\Theta$ of 2170 s. This reference was used throughout the subsequent analysis to determine the binding potentials relative to non-displaceable accumulation $\left(\mathrm{BP}_{\mathrm{ND}}\right)$.

We did note diffuse $A \beta / A \beta P P$ immunostaining of both frontal and temporal cortices with $6 \mathrm{E} 10$, however these deposits did not bind $\left[{ }^{11} \mathrm{C}\right] \mathrm{PiB}$ to the same degree as the deposits in the cerebellum, implying that dogs with CCD are not afflicted with a typical form of $\mathrm{AD}$ (Figure 4). Because the major part of amyloid is not usually found in cerebellum of humans with $\mathrm{AD}$, unlike in the brains of the present group of CCD dogs, CCD may instead be a better model of genetic AD in humans, or hereditary cerebral hemorrhage with amyloidosis and prion diseases, also in humans (Watanabe and Duchen, 1993; Ghiso and Frangione, 2001; Klunk et al., 2007). However, these hypotheses are speculative and yet to be confirmed in families of dogs.

The high degree of $\left[{ }^{11} \mathrm{C}\right] \mathrm{PiB}$ binding in the cerebellum, with few if any extracellular deposits and large amounts of intracellular $\mathrm{A} \beta$ or $\mathrm{A} \beta \mathrm{PP}$, or both, suggests that $\left[{ }^{11} \mathrm{C}\right] \mathrm{PiB}$ binding may be used to distinguish between intracellular $A \beta$ and $A \beta P P$ deposits in the dog cerebellum. Aged dogs with CCD spontaneously exhibit diffuse $A \beta$ deposits in the cerebral cortex that are similar to those found in early AD brains (Cummings et al., 1993, 1996; Satou et al., 1997; Anderson et al., 2000; Head et al., 2008; Yu et al., 2011). In addition, the diffuse $A \beta$ deposits in the canine brain are immunopositive for $A \beta_{1-42}$ and do not stain with Congo red and thioflavine, unlike proven cerebral amyloid angiopathy (Uchida et al., 1992; Cummings et al., 1993, 1996; Satou et al., 1997).

The high proportion of diffuse to compact $A \beta$ deposits in dogs with CCD theoretically should not pose a problem, because previous investigations show that $\left[{ }^{11} \mathrm{C}\right] \mathrm{PiB}$ in tissue from $\mathrm{AD}$ patients also recognizes diffuse $A \beta$ deposits in addition to compact $A \beta$ deposits (Klunk et al., 2003; Lockhart et al., 2007). Hence [ $\left.{ }^{11} \mathrm{C}\right] \mathrm{PiB}$ in principle would be a tracer suitable for outlining the distribution of $\mathrm{A} \beta$ deposits in the aged dog with CCD with a cranial to caudal distribution. The results point to a pattern of $\left[{ }^{11} \mathrm{C}\right] \mathrm{PiB}$ retention in the dog brain, which is occasionally seen in humans. We also found a discrepancy between the distributions of $A \beta$ and $\mathrm{A} \beta \mathrm{PP}$, when we visually correlated $\left[{ }^{11} \mathrm{C}\right] \mathrm{PiB}$ images with regionally matched images of the post-mortem histological material stained with $6 \mathrm{E} 10$. In a study of a cohort of $10 \mathrm{AD}$ patients, one patient who met the histopathological criteria for AD had PiB-refractory PET images (Rosen et al., 2010). This patient had more vascular $\mathrm{A} \beta$, higher levels of insoluble $A \beta_{1-40}$ and $A \beta_{1-42}$, and a higher ratio of $A \beta_{1-40}$ to $A \beta_{1-42}$, compared to brain tissue from the nine other $\mathrm{AD}$ patients.

Studies of $\left[{ }^{11} \mathrm{C}\right] \mathrm{PiB}$ imaging in PS1/APP mice and post mortem histological analysis have shown diverging results of different attempts to find a correlation between the $\left[{ }^{11} \mathrm{C}\right] \mathrm{PiB}$ images and $\mathrm{A} \beta$ deposits in vitro (Klunk et al., 2005a; Manook et al., 2012). The negative results may be explained in part by the presence of lower affinity $\mathrm{PiB}$ binding sites on $\mathrm{A} \beta$ deposits in the transgenic mouse brains than in AD brains (Klunk et al., 2005a; Toyama et al., 2005). This explanation implies that a part of the PiB binding in mouse and dog brains may be selective for a specific conformation of $\mathrm{A} \beta$ deposits found in $\mathrm{AD}$ patients at the low nanomolar concentrations used in PET studies. This hypothetical selectivity of $\mathrm{PiB}$ is consistent with another study of transgenic mice, in which it was concluded that the detectability of amyloid by $\mathrm{PiB}$ depends on the accumulation of specific $A \beta$ subtypes. This explanation was proposed as well in a study of primate brain homogenates, which showed markedly reduced binding to $\mathrm{PiB}$ compared to human brain homogenates (Rosen et al., 2011).

This study gave evidence that the distribution of $\left[{ }^{11} \mathrm{C}\right] \mathrm{PiB}$ retention in dogs with CCD fundamentally is different from that seen in humans with $\mathrm{AD}$. The results of the study support previous studies showing that $\left[{ }^{11} \mathrm{C}\right] \mathrm{PiB}$ is a complex tracer in animals and humans and more investigations of this radiotracer, including displacement studies are needed.

\section{ACKNOWLEDGMENTS}

The authors would like to acknowledge and thank the technical staff at the PET Center and the MR NeuroResearch units at Aarhus University Hospital, Denmark for technical assistance. In addition, we would like to acknowledge Margit Marquard Jensen, Veterinary nurse at The Department of Clinical Veterinary and Animal Sciences, University of Copenhagen for assistance during the anesthetic procedure. The authors would like to acknowledge and thank associate Prof. Pall Skuli Leifsson and the technical staff at the Department of Veterinary Disease Biology, Faculty of Life Science, University of Copenhagen, Denmark for help with collecting brains from dogs that were euthanized during the study. We would also like to thank Trine W. Mikkelsen, Lise M. Fitting, and Anette Bro at the Center of Experimental Neuroscience (CENSE), Aarhus, Denmark for laboratory preparation of the brains for the study.

\section{REFERENCES}

Aho, L., Pikkarainen, M., Hiltunen, M., Leinonen, V., and Alafuzoff, I. (2010). Immunohistochemical visualization of amyloid-beta protein precursor and amyloid-beta in extra- and intracellular compartments in the human brain. J. Alzheimers Dis. 20, 1015-1028. doi:10.3233/JAD-2010-091681

Andersen, F., Watanabe, H., Bjarkam, C., Danielsen, E. H., and Cumming, P. (2005). Pig brain stereotaxic standard space: mapping of cerebral blood flow normative values and effect of MPTP-lesioning. Brain Res. Bull. 66, 17-29. doi:10.1016/j.brainresbull.2005.02.033

Anderson, A. J., Ruehl, W. W., Fleischmann, L. K., Stenstrom, K., Entriken, T. L., and Cummings, B. J. (2000). DNA damage and apoptosis in the aged canine brain: relationship to A beta deposition in the absence of neuritic pathology. Prog. Neuropsychopharmacol. Biol. Psychiatry 24, 787-799. doi:10.1016/S02785846(00)00106-8

Bacskai, B. J., Frosch, M. P., Freeman, S. H., Raymond, S. B., Augustinack, J. C., Johnson, K. A., et al. (2007). Molecular imaging with Pittsburgh compound B confirmed at autopsy: a case report. Arch. Neurol. 64, 431-434. doi:10.1001/archneur.64.3.431

Bjarkam, C. R., Pedersen, M., and Sorensen, J. C. (2001). New strategies for embedding, orientation and sectioning of small brain specimens enable direct correlation to MR-images, brain atlases, or use of unbiased stereology. J. Neurosci. Methods 108, 153-159. doi:10.1016/S0165-0270(01)00383-1

Blomquist, G., Engler, H., Nordberg, A., Ringheim, A., Wall, A., Forsberg, A., et al. (2008). Unidirectional influx and net accumulation of PIB. Open Neuroimag. J. 2, 114-125. doi:10.2174/1874440000802010114

Cocosco, C. A., Zijdenbos, A. P., and Evans, A. C. (2003). A fully automatic and robust brain MRI tissue classification method. Med. Image Anal. 7, 513-527. doi:10.1016/S1361-8415(03)00037-9

Colle, M. A., Hauw, J. J., Crespeau, F., Uchihara, T., Akiyama, H., Checler, F., et al. (2000). Vascular and parenchymal A beta deposition in the aging dog: correlation with behavior. Neurobiol. Aging 21, 695-704. doi:10.1016/S0197-4580(00) 00113-5 
Collins, D. L., Neelin, P., Peters, T. M., and Evans, A. C. (1994). Automatic 3D intersubject registration of MR volumetric data in standardized Talairach space. J. Comput. Assist. Tomogr. 18, 192-205.

Cummings, B. J., Satou, T., Head, E., Milgram, N. W., Cole, G. M., Savage, M. J., et al. (1996). Diffuse plaques contain C-terminal A beta(42) and not A beta(40): evidence from cats and dogs. Neurobiol. Aging 17, 653-659. doi:10.1016/S01974580(96)00062-0

Cummings, B. J., Su, J. H., Cotman, C. W., White, R., and Russell, M. J. (1993). Beta-amyloid accumulation in aged canine brain - a model of early plaqueformation in Alzheimer's-disease. Neurobiol. Aging 14, 547-560. doi:10.1016/ 0197-4580(93)90038-D

Dua-Sharma, S., Jacobs, H. L., and Sharma, K. N. (1970). The Canine Brain in Stereotaxic Coordinates Full Sections in Frontal, Sagittal, and Horizontal Planes. Cambridge, MA: MIT Press.

Edison, P., Hinz, R., Ramlackhansingh, A., Thomas, J., Gelosa, G., Archer, H. A., et al. (2012). Can target-to-pons ratio be used as a reliable method for the analysis of [11C]PIB brain scans? Neuroimage 60, 1716-1723. doi:10.1016/j.neuroimage. 2012.01.099

Ghiso, J., and Frangione, B. (2001). Cerebral amyloidosis, amyloid angiopathy, and their relationship to stroke and dementia. J. Alzheimers Dis. 3, 65-73.

Gjedde, A., Aanerud, J., Braendgaard, H., and Rodell, A. B. (2013). Blood-brain transfer of Pittsburgh compound B in humans. Front. Aging Neurosci. 5:70. doi:10.3389/fnagi.2013.00070

Gulyas, B., Spenger, C., Beliczai, Z., Gulya, K., Kasa, P., Jahan, M., et al. (2012). Distribution and binding of 18F-labeled and 125I-labeled analogues of ACI-80, a prospective molecular imaging biomarker of disease: a whole hemisphere post mortem autoradiography study in human brains obtained from Alzheimer's disease patients. Neurochem. Int. 60, 153-162. doi:10.1016/j.neuint. 2011.10.010

Hardy, J., and Selkoe, D. J. (2002). The amyloid hypothesis of Alzheimer's disease: progress and problems on the road to therapeutics. Science 297, 353-356. doi:10.1126/science. 1072994

Head, E., Callahan, H., Muggenburg, B. A., Cotman, C. W., and Milgram, N. W. (1998). Visual-discrimination learning ability and beta-amyloid accumulation in the dog. Neurobiol. Aging 19, 415-425. doi:10.1016/S0197-4580(98)00084-0

Head, E., Pop, V., Vasilevko, V., Hill, M., Saing, T., Sarsoza, F., et al. (2008). A twoyear study with fibrillar beta-amyloid (Abeta) immunization in aged canines: effects on cognitive function and brain Abeta. J. Neurosci. 28, 3555-3566. doi:10.1523/JNEUROSCI.0208-08.2008

Ikonomovic, M. D., Klunk, W. E., Abrahamson, E. E., Mathis, C. A., Price, J. C. Tsopelas, N. D., et al. (2008). Post-mortem correlates of in vivo PiB-PET amyloid imaging in a typical case of Alzheimer's disease. Brain 131, 1630-1645. doi:10.1093/brain/awn016

Jack, C. R., Knopman, D. S., Jagust, W. J., Shaw, L. M., Aisen, P. S., Weiner, M W., et al. (2010). Hypothetical model of dynamic biomarkers of the Alzheimer's pathological cascade. Lancet Neurol. 9, 119-128. doi:10.1016/S1474-4422(09) 70299-6

Kiatipattanasakul, W., Nakamura, S., Hossain, M. M., Nakayama, H., Uchino, T., Shumiya, S., et al. (1996). Apoptosis in the aged dog brain. Acta Neuropathol. 92, 242-248. doi:10.1007/s004010050514

Klunk, W. E., Engler, H., Nordberg, A., Wang, Y., Blomqvist, G., Holt, D. P., et al. (2004). Imaging brain amyloid in Alzheimer's disease with Pittsburgh compound-B. Ann. Neurol. 55, 306-319. doi:10.1002/ana.20009

Klunk, W. E., Lopresti, B. J., Ikonomovic, M. D., Lefterov, I. M., Koldamova, R. P., Abrahamson, E. E., et al. (2005a). Binding of the positron emission tomography tracer Pittsburgh compound-B reflects the amount of amyloid-beta in Alzheimer's disease brain but not in transgenic mouse brain. J. Neurosci. 25, 10598-10606. doi:10.1523/JNEUROSCI.2990-05.2005

Klunk, W. E., Lopresti, B. J., Ikonomovic, M. D., Lefterov, I. M., Koldamova, R. P., Abrahamson, E. E., et al. (2005b). Binding of the positron emission tomography tracer Pittsburgh compound-B reflects the amount of amyloid-beta in Alzheimer's disease brain but not in transgenic mouse brain. J. Neurosci. 25, 10598-10606. doi:10.1523/JNEUROSCI.2990-05.2005

Klunk, W. E., Price, J. C., Mathis, C. A., Tsopelas, N. D., Lopresti, B. J., Ziolko, S. K., et al. (2007). Amyloid deposition begins in the striatum of presenilin1 mutation carriers from two unrelated pedigrees. J. Neurosci. 27, 6174-6184. doi:10.1523/JNEUROSCI.0730-07.2007
Klunk, W. E., Wang, Y., Huang, G. F., Debnath, M. L., Holt, D. P., Shao, L., et al. (2003). The binding of 2-(4'-methylaminophenyl)benzothiazole to postmortem brain homogenates is dominated by the amyloid component. J. Neurosci. 23, 2086-2092.

Lockhart, A., Lamb, J. R., Osredkar, T., Sue, L. I., Joyce, J. N., Ye, L., et al. (2007). PIB is a non-specific imaging marker of amyloid-beta Abeta peptide-related cerebral amyloidosis. Brain 130, 2607-2615. doi:10.1093/brain/awm191

Maes, F., Collignon, A., Vandermeulen, D., Marchal, G., and Suetens, P. (1997). Multimodality image registration by maximization of mutual information. IEEE Trans. Med. Imaging 16, 187-198. doi:10.1109/42.563664

Manook, A., Yousefi, B. H., Willuweit, A., Platzer, S., Reder, S., Voss, A., et al. (2012) Small-animal PET imaging of amyloid-beta plaques with [11C]PiB and its multimodal validation in an APP/PS1 mouse model of Alzheimer's disease. PLoS ONE 7:e31310. doi:10.1371/journal.pone.0031310

McKhann, G. M., Knopman, D. S., Chertkow, H., Hyman, B. T., Jack, J., Kawas, C. H., et al. (2011). The diagnosis of dementia due to Alzheimer's disease: recommendations from the national institute on aging-Alzheimer's association workgroups on diagnostic guidelines for Alzheimer's disease. Alzheimers Dement. 7, 263-269. doi:10.1016/j.jalz.2011.03.005

Mintun, M. A., Larossa, G. N., Sheline, Y. I., Dence, C. S., Lee, S. Y., Mach, R. H., et al. (2006). [11C]PIB in a nondemented population: potential antecedent marker of Alzheimer disease. Neurology 67, 446-452. doi:10.1212/01.wnl.0000228230. 26044.a4

Moller, M., Rodell, A., and Gjedde, A. (2009). Parametric mapping of 5HT1A receptor sites in the human brain with the Hypotime method: theory and normal values. J. Nucl. Med. 50, 1229-1236. doi:10.2967/jnumed.108.053322

Nielsen, M. S., Bjarkam, C. R., Sorensen, J. C., Bojsen-Moller, M., Sunde, N. A., and Ostergaard, K. (2007). Chronic subthalamic high-frequency deep brain stimulation in Parkinson's disease-a histopathological study. Eur. J. Neurol. 14, 132-138. doi:10.1111/j.1468-1331.2006.01569.x

Osella, M. C., Re, G., Odore, R., Girardi, C., Badino, P., Barbero, R., et al. (2007). Canine cognitive dysfunction syndrome: prevalence, clinical signs and treatment with a neuroprotective nutraceutical. Appl. Anim. Behav. Sci. 105, 297-310. doi:10.1016/j.applanim.2006.11.007

Price, J. C., Klunk, W. E., Lopresti, B. J., Lu, X., Hoge, J. A., Ziolko, S. K., et al. (2005). Kinetic modeling of amyloid binding in humans using PET imaging and Pittsburgh compound-B. J. Cereb. Blood Flow Metab. 25, 1528-1547. doi:10.1038/sj.jcbfm.9600146

Pugliese, M., Geloso, M. C., Carrasco, J. L., Mascort, J., Michetti, F., and Mahy, N. (2006a). Canine cognitive deficit correlates with diffuse plaque maturation and S100 beta (-) astrocytosis but not with insulin cerebrospinal fluid level. Acta. Neuropathol. 111, 519-528. doi:10.1007/s00401-006-0052-1

Pugliese, M., Mascort, J., Mahy, N., and Ferrer, I. (2006b). Diffuse beta-amyloid plaques and hyperphosphorylated tau are unrelated processes in aged dogs with behavioral deficits. Acta Neuropathol. 112, 175-183. doi:10.1007/s00401-0060087-3

Rodell, A., Aanerud, J., Braendgaard, H., and Gjedde, A. (2013). Washout allometric reference method (WARM) for parametric analysis of [11C]PIB in human brains. Front. Aging Neurosci. 5:45. doi:10.3389/fnagi.2013.00045

Rofina, J. E., van Ederen, A. M., Toussaint, M. J. M., Secreve, M., van der Spek, A., van der Meer, I., et al. (2006). Cognitive disturbances in old dogs suffering from the canine counterpart of Alzheimer's disease. Brain Res. 1069, 216-226. doi:10.1016/j.brainres.2005.11.021

Rosen, R. F., Ciliax, B. J., Wingo, T. S., Gearing, M., Dooyema, J., Lah, J. J., et al. (2010). Deficient high-affinity binding of Pittsburgh compound B in a case of Alzheimer's disease. Acta Neuropathol. 119, 221-233. doi:10.1007/s00401-0090583-3

Rosen, R. F., Farberg, A. S., Gearing, M., Dooyema, J., Long, P. M., Anderson, D. C., et al. (2008). Tauopathy with paired helical filaments in an aged chimpanzee. J. Comp. Neurol. 509, 259-270. doi:10.1002/cne.21744

Rosen, R. F., Walker, L. C., and Levine, H. III (2011). PIB binding in aged primate brain: enrichment of high-affinity sites in humans with Alzheimer's disease. Neurobiol. Aging 32, 223-234. doi:10.1016/j.neurobiolaging.2009.02.011

Sarasa, L., Gallego, C., Monleón, I., Olvera, A., Canudas, J., Montañés, M., et al. (2010). Cloning, sequencing and expression in the dog of the main amyloid precursor protein isoforms and some of the enzymes related with their processing Neuroscience 171, 1091-1101. doi:10.1016/j.neuroscience.2010.09.042 
Satou, T., Cummings, B. J., Head, E., Nielson, K. A., Hahn, F. F., Milgram, N. W., et al. (1997). The progression of beta-amyloid deposition in the frontal cortex of the aged canine. Brain Res. 774, 35-43. doi:10.1016/S0006-8993(97)81684- 8

Sled, J. G., Zijdenbos, A. P., and Evans, A. C. (1998). A nonparametric method for automatic correction of intensity nonuniformity in MRI data. IEEE Trans. Med. Imaging 17, 87-97. doi:10.1109/42.668698

Sorensen, J. C., Bjarkam, C. R., Danielsen, E. H., Simonsen, C. Z., and Geneser, F. A. (2000). Oriented sectioning of irregular tissue blocks in relation to computerized scanning modalities: results from the domestic pig brain. J. Neurosci. Methods 104, 93-98. doi:10.1016/S0165-0270(00)00330-7

Toyama, H., Ye, D., Ichise, M., Liow, J.-S., Cai, L., Jacobowitz, D., et al. (2005). PET imaging of brain with the beta-amyloid probe, 11C6-OH-BTA-1, in a transgenic mouse model of Alzheimer's disease. Eur. J. Nucl. Med. Mol. Imaging 32, 593-600. doi:10.1007/s00259-005-1780-5

Uchida, K., Tani, Y., Uetsuka, K., Nakayama, H., and Goto, N. (1992). Immunohistochemical studies on canine cerebral amyloid angiopathy and senile plaques. J. Vet. Med. Sci. 54, 659-667. doi:10.1292/jvms.54.659

Vila, C., Savolainen, P., Maldonado, J. E., Amorim, I. R., Rice, J. E., Honeycutt, R. L., et al. (1997). Multiple and ancient origins of the domestic dog. Science 276, 1687-1689. doi:10.1126/science.276.5319.1687

Villemagne, V. L., Klunk, W. E., Mathis, C. A., Rowe, C. C., Brooks, D. J., Hyman, B. T., et al. (2012). Abeta Imaging: feasible, pertinent, and vital to progress in Alzheimer's disease. Eur. J. Nucl. Med. Mol. Imaging 39, 209-219. doi:10.1007/s00259-011-2045-0

Watanabe, H., Andersen, F., Simonsen, C. Z., Evans, S. M., Gjedde, A., and Cumming, P. (2001). MR-based statistical atlas of the Gottingen minipig brain. Neuroimage 14, 1089-1096. doi:10.1006/nimg.2001.0910
Watanabe, R., and Duchen, L. W. (1993). Cerebral amyloid in human prion disease. Neuropathol. Appl. Neurobiol. 19, 253-260. doi:10.1111/j.1365-2990.1993. tb00435.x

Yu, C. H., Song, G. S., Yhee, J. Y., Kim, J. H., Im, K. S., Nho, W. G., et al. (2011). Histopathological and immunohistochemical comparison of the brain of human patients with Alzheimer's disease and the brain of aged dogs with cognitive dysfunction. J. Comp. Pathol. 145, 45-58. doi:10.1016/j.jcpa.2010.11.004

Conflict of Interest Statement: The research in this paper was conducted in the absence of any commercial or financial relationships that could be construed as a potential conflict of interest to authors.

Received: 17 May 2013; accepted: 10 December 2013; published online: 30 December 2013.

Citation: Fast R, Rodell A, Gjedde A, Mouridsen K, Alstrup AK, Bjarkam CR, West $M J$, Berendt $M$ and Møller A (2013) PiB fails to map amyloid deposits in cerebral cortex of aged dogs with canine cognitive dysfunction. Front. Aging Neurosci. 5:99. doi: 10.3389/fnagi.2013.00099

This article was submitted to the journal Frontiers in Aging Neuroscience.

Copyright (c) 2013 Fast, Rodell, Gjedde, Mouridsen, Alstrup, Bjarkam, West, Berendt and Møller. This is an open-access article distributed under the terms of the Creative Commons Attribution License (CC BY). The use, distribution or reproduction in other forums is permitted, provided the original author(s) or licensor are credited and that the original publication in this journal is cited, in accordance with accepted academic practice. No use, distribution or reproduction is permitted which does not comply with these terms. 